\title{
Exploring Business Sustainability Factors of Malaysian Agribusiness Small Medium Enterprises (ASMEs)
}

\author{
Assoc. Prof. Dr. Nalini Arumugam, \\ Lecturer at Faculty of Bioresources and Food Industry \\ Universiti Sultan Zainal Abidin (Besut Campus), \\ Terengganu, Malaysia. \\ Alageasan Dhayalan \\ Graduate Student at Faculty of Bioresources and Food Industry \\ Universiti Sultan Zainal Abidin, (Main Campus) \\ Terengganu, Malaysia. \\ Asso. Prof. Dr. Fakhrul Anwar Zainol \\ Lecturer at Faculty of Economy and Management Sciences \\ Universiti Sultan Zainal Abidin, (Main Campus), \\ Terengganu, Malaysia. \\ Dr. Bonaventure Boniface \\ Lecturer at Faculty of Sustainable Agriculture \\ Universiti Malaysia Sabah, Jalan UMS \\ 88400, Kota Kinabalu \\ Sabah, Malaysia
}

\begin{abstract}
Business sustainability is a new field of interest among business scholars. Its conceptual ambiguity and lack of sector specific study had motivated this research. The aim of this study is to explore the factors associated with business sustainability of Malaysian Agribusiness Small Medium Enterprises (ASMEs). A total of 100 respondents from six states throughout Malaysia participated in this study by answering Likert scale questions. A theoretical framework consisting of one dependent and seven independent variables were rectified using the exploratory factor analysis (EFA) method. As a result, the instrument was identified adequate and reliable to explore seven (7) factors that influence business sustainability among Malaysian ASMEs, including (i) business passion and motivations, (ii) owner and business traits, (iii) business planning, (iv) organisational management, (v) resource management, (vi) production and marketing management and (vii) business relationships.
\end{abstract}

Keyword: Agribusiness SMEs, Exploratory Factor Analysis (EFA), financial and non-financial performances, small business and Stakeholders Theory.

\section{Introduction}

According to Malaysian SMEs Development Plan 2016, there are 6,708 registered agricultural based SMEs which accounts for 1.04\% of SMEs nationwide (NSDC, 2017). Despite of their limited establishment, they had contributed between 4.0 - 4.5\% to the Malaysian Gross Domestic Production (GDP) from the year 2011-2015 (NSDC, 2017). However, their growth and contribution is often fluctuating and highly dependent on government support programs. Apart from their financial contribution, agricultural SMEs are also responsible in providing job opportunity and food for the community. Previous studies had highlighted five major challenges of agribusinesses, including high number of smallholders (Mahfoor, Mad Nasir and Ismail, 2001), structural challenges (Rozhan, 2015), low rate of thrive (Ramli et al, 2015), resource scarcity hindering technological adoption (Ramayah et al, 2016) and preliminary failure - within 5 years of establishment (Mudavanhu et al, 2011; Noor and Pi-Shen, 2009; Olabisi and Olagbemi, 2011). Although various programs and initiatives are provided by the government, growth and success of ASMEs are minimal. 
Many small business ventures tend to close down as soon as they begin. According to Semistatus and Rainer (2014), throughout its lifecycle, an enterprise would experience periods of growth, aging and death or decline of growth rate. Thorough understanding of factors influencing sustainability of a business is important for businesses to handle and recover from stagnation. Lack of sector-specific study and focus on thenon-financial performance of agricultural based small businesses had motivated this study. Therefore, this study would contribute to the knowledge gap in term of sector specificity and examination of both financial and non-financial performances. The aim of this study is to explore the factors associated with business sustainability of Malaysian Agribusiness Small Medium Enterprises (ASMEs).

\section{Theoretical approaches on business sustainability}

As reported by Arumugam et al (2017a), three main theories are utilized in explaining the concept of business sustainability, namely institutional theory, resource-based view (RBV) and stakeholders' theory. Institutional theory measures sustainability through rules and regulations compliances of a firm (Arumugam et al, 2017a). These rules and regulations vary according to the historical and socio-political variances. Thus, any practice acceptable as sustainable in a region or period of time, are always subjected to variances and changes. For instance, in the oil palm industry, Roundtable on Sustainable Palm Oil (RSPO) is the commonly accepted standard for production and supply sustainability. However, smallholders in Malaysia were found facing difficulty in meeting those standards, thus Malaysia rectified a different standard formulated by stakeholders aspiration known as Malaysian Sustainable Palm Oil (MSPO) ("Comparison", n.d., para. 5). Later in 2015, Malaysia and Indonesia had merged their standards, namely MSPO and Indonesian Sustainable Palm Oil (ISPO) Standard forming a new standard known as the Council of Palm Oil Producing countries (CPOPC) Standards(“Comparison”, n.d., para.7). This phenomenon clearly shows how standards vary by countries and are subjected to changes.

Resource based view, on the other hand, examines the effectiveness of a firm mix-matching its strengths and weaknesses based on available tangible and intangible resources in order to thrive in tight economic environment (Arumugam et al, 2017a).Competitive advantage of a firm is the indicator of sustainability according to this theory (Darcy et al, 2014). Thus, RBV is focused on the progression of the business in any kind of circumstances to perform better than its competitors. However, this theory had been criticised by several academicians for their lack of managerial implications, infinite goal and limited applicability in small firms, which definitely has limited resource compared to their large scale competitors (Kraaijenbrink, Spender and Groen, 2009). Therefore, although RBV has set an aspiration, that is in order to be sustainable, a firm should be competitive, the gap of how to attain that goal need to be filled.

Stakeholder's theory, in contrast to RBV, places the measure of sustainability on the satisfaction of stakeholders (Arumugam et al, 2017a). Friedrich, Heyder and Theuvsen (2013) had categorized stakeholders by their aloofness with the firm, namely internal (owner and employee), external (fellow business, customers and government) and distal (society). Once the stakeholders are satisfied with a business, their trust and commitment would add value to the firm to revamp and sustain in the industry through hardships. This theory is the most used among scholars measuring sustainability of small agribusinesses (Arumugam et al, 2017a). The challenge of this measure is, stakeholder's satisfaction are often paradoxically related. For instance, high end product price would be satisfactory for the owner, but not for the customer. Therefore, transparency and rapid communication is important to seek for and balance the expectations of stakeholders in order for a business to sustain in the industry.

\section{Methodology}

\section{Population and sampling}

The target population of this study is micro, small and medium scale businesses based on agricultural products and services at six states in Malaysia, namely Terengganu, Perak, Selangor, Johor, Sabah and Sarawak. Upon receiving the list of owners available in each state, 100 respondents were selected randomly. Then, questionnaire were distributed and recollected after filled independently by respondents. Confidentiality of the data provided is ensured in the front page of each questionnaire.

\section{Questionnaire development}

The questionnaire contained four parts, namely the sustainability level of business (Part A), business sustainability factors (Part B), Owner's profile (Part C) and business details (Part D). In part A, respondents were asked to score their level of satisfaction to Likert scale at an interval of $1-5$. For part B, respondents' level of agreement was scored via a Likert Scale of $1-5$ to statements regarding influence of each factor on business sustainability. 
Part C and D contained closed-ended questions. A total of seven independent variables were assumed to effect business sustainability upon revising previous literatures. A total of eight (8) variables are involved in this study which includes a dependent variable (DV) and seven (7) independent variables (IV 1 - IV7).

\section{Research constructs}

\section{Business Sustainability (DV)}

In order to venture into the knowledge of business sustainability, it is important to know that focusing solely on the financial achievements of a business is a traditional mistake (Falshaw and Glaister, 2006). They measured satisfaction of the owner to the financial achievements (profit, sales, market share, after tax return, sales to asset ratio and overall) of his/her firm to address sustainability. Gao and Bansal (2013) also had stressed the importance of examining the nonfinancial performances, which include satisfaction of business owner on his/her business, workers and customers. Copper and Artz (1999) argued that satisfaction is a fundamental measurement of small business success and Mahto et al (2010) stated that it is a better measurement of performance compared to the financial excellence. This is because financial gains are often inconsistent among small business and only a satisfied owner would sustain his business in hardship and rejuvenate into the industry.Therefore, in this study framework

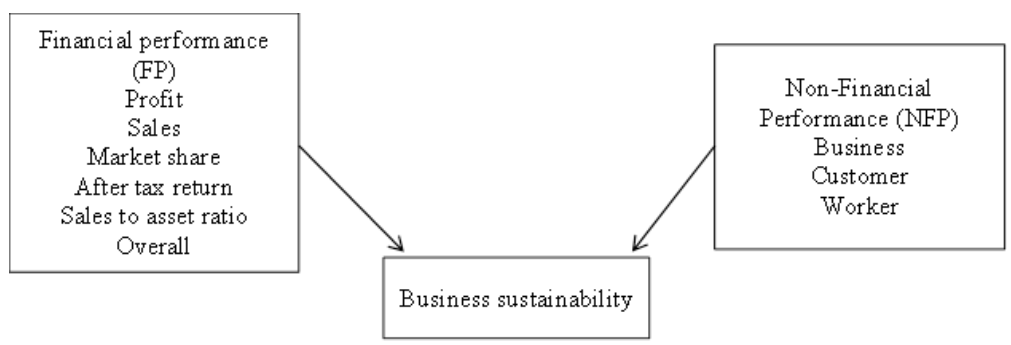

Figure 1 Framework for business sustainability

we integrated both financial and non-financial measures of business sustainability (dependent variable). For each of the measures, the owner's satisfaction was assigned using the Likert scale.

Business Passion and Motivation (IV 1)

Prolonged interest fueled by emotional desire is known as passion. According to Stephen, Hart and Mickiewicz (2015), passionate entrepreneurs are motivated by financial gain, better work autonomy and family legacy. This claim had been rectified for small scale agribusiness in Malaysia in the research of Arumugam et al (2017b). They found that business start-up might occur due to harmonious passion which depends solely on intrinsic motivation. However, for a business to continuously overcome challenges and sustain in the industry, the owner would possess obsessive passion which are influenced by extrinsic motivations, namely financial gain, work autonomy and family legacy. Owners motivated by financial gain are more prone to practice product and process innovation in their business (Arumugam et al, 2017b).Family legacy, on the other hand, influences the desire of an owner to bequeath his/her business by transferring skills and knowledge to their next generation (Arumugam et al, 2017b). Time flexibility is utilised by autonomymotivated owners to alternate schedules according to business need and improve performances (Arumugam et al, 2017b).

\section{Owner and Business Traits (IV 2)}

According to Escalante and Turvey (2006),Knight's had classified business owner traits into a hierarchy ranging from craft person level to promoter level and general manager level. When a proprietor is equipped with only the set of traits for a craft person (producer), he/she would neither market well the products nor manage well the business. According to Mohd Mansor (2014), marketing incompetence among local agribusiness owners had caused longer supply chain and exploitation by middlemen in Malaysia. The qualitative study by Arumugam et al (2017b) also had recorded the admittance of local agribusiness practitioners to this issue which hinders their optimal financial gain and sustainability in the supply chain. Mudavanhu et al (2011) had argued that better quality decisions, those reduce risk of failure are more likely to arise from well-educated owners. In addition, better educational level of business owner had been the reason for easier technological adoption among small businesses as reported by KiatGan and Mahmoud Khalid (2013). Apart from traits of the owner, business traits, including age (Escalante and Turvey, 2006) scale (Mudavanhu et al, 2011) and location (Okoye et al, 2013) were also found to influence small business sustainability. Escalante and Turvey (2006) proposed that, as age and experience accumulates, a small firm gains maturity to overcome challenges and act appropriately to the economic climate and sustain in the industry. 
Mudavanhu et al (2011) had utilised two production theories in explaining struggles of a small sized firm to be sustainable. The production theory explains how small firms face difficulty to attain economies of scale due to minimal efficiency scale. Besides that, technological capabilities theory described that small firms are lack of collateral to attract private funding assistance and investment, thus face harder challenges to implement new technologies and avert from attaining efficiency which leads to unsustainability. Business location was found to influence sustainability through access to market and local economic developments by Okoye et al (2013).

\section{Business Planning (IV 3)}

A famous quote of Franklin Benjamin states that "failing to plan is planning to fail". Skill execution of an entrepreneur to paddle his/her business towards success and sustainability starts at the planning level. A good business plan, according to Ligthelm (2010) should take into account the risks, competitors analysis and new venture opportunities. Arumugam et al (2017b) had explained their concern on local small agribusiness owners who have aim to expand their businesses, but are unaware of the important aspects of good business plan. Mohd Mansor (2014) had stated that, poor or incomplete business planning is one of the reasons for immediate withdrawal of local small scale agribusinesses. Thus, the ability of owner to construct, execute, revise and alternate his/her business plan according to current business environment affects the wellbeing of a business.

\section{Organisational management (IV 4)}

According to Escalante and Turvey (2006), small business owners often face dilemma of personal control and prestige. They are tend to be reluctant to delegate tasks within the organisation members causing execution barrier and management incompetence. This is also an issue of business sustainability, as available resources are not utilised systematically. Thus, trusting the ability of employees and delegating tasks appropriate to their set of skills and experiences is necessary for a business to be sustainable.

\section{Resource Management (IV 5)}

Both tangible and intangible resource management are found to influence sustainability of a business in previous studies. As for the intangible (knowledge) management, both ability and commitment of employees is important for knowledge based value creation which could lead to specialization and competitive advantage (Wiklund and Shepherd, 2003). Malaysian small agribusiness owners agreed that they receive better commitment from foreign labors compared to local manpower (Arumugam et al, 2017b). Siti Sarah, Lawrence and Maimunah (2009) on the other hand reported that local small agribusinesses are lack of investment and system for training and skill development. Both this criterion would lead to difficulty in growth and sustenance of local small agribusiness. In contrast to that, certain local agribusinesses hire local manpower by contract or collaborate with them in providing training as partnership opportunity (Arumugam et al, 2017b). This action is expected to positively influence business sustainability among

\section{Malaysian ASMEs.}

Tangible resource management is also found equally important. Capital generation, cash flow, debt management and reinvestment are important financial management aspects that determine business sustainability (CODIT, 2009). Appropriate financial record keeping and accounting are important to build trust among investors and sustain during hardships. Besides that, lack of financial asset in small business also caused them to invest only in money generating activities (Escalante and Turvey, 2006). This in turn caused inadequate and limited in-house-technology and high dependence on government support for this reason. Arumugam et al (2017b) also recorded the inability of smallholders to access local innovations due to financial constraint. Apart from that, certificate compliance also hindered by lack of capital. Thus, availability and ability to manage financial resource is also a factor regulating business sustainability.

\section{Production and Marketing Management (IV 6)}

The ability of a business to adjust with demand and continuously offer viable, innovated products into the market aids it to survive several years subsequently after entry as reported by Okoye et al (2013). Although performance of a product is necessary to attract customers (Ramukumba, 2014), their demand are subject to changes and sophistications. Thus, investing on research and development of a product could improve both demand condition and competitive advantage of the business (Dlamini, 2014). Arumugam et al (2017b) also had reported Malaysian ASMEs owners alter their products due to climatic and demand changes. Apart from that, utilization of by products also gives new venture opportunity to high-end product development. In short, production management is important to ensure the business continuityin relevance to current market demand. However, marketing management is another important regulator of sustainability, as for a good product to reach the consumer, good marketing strategy is crucial. 
Skill inadequacy might lead to reputational challenge if the product in the market and cause both financial and nonfinancial loss to the business (Escalante and Turvey, 2006). Thus, production and marketing management are simultaneously affecting business sustainability.

\section{Business relationships (IV 7)}

There are three types of business relationships reported affecting sustainability of businesses, namely Business to Business (B2B), Business to Customer (B2C) and Business to Government (B2G) relationships. B2B is the cooperation among businesses to minimize competition, facilitate product commercialisation, better bargaining power, access to better prices, credit assistance and technical training (Michel-Villareal and Vilalta-Perdomo, 2016). It is found beneficial to reduce risks and improve potential of businesses. Arumugam et al (2017b) also stated that producers need support mechanism to complete the supply chain. Thus, efficient B2B is expected to fulfill the needs of fellow owners and facilitate mutual success. The second type of relationship, namely B2C is important to form customer loyalty, which ranges from behavioral, to attitudinal and composite loyalties (Bonaventure, Gyau and Stringer, 2012). This in turn affects the increase in market share and sales volume which affects the financial gain of the firm. Providing after sales services leads to word-of-mouth marketing which increases reputation of the business within the industry (Arumugam et al, 2017b). As for B2G, good understanding and information flow is important for both bottom-up and top-down development approaches. However, high level of bureaucracy is found to hinder or delay access to assistances which in turn reduces efficiency of businesses (Ali Salman and Ndubisi, 2006; Arumugam et al, 2017b). Thus, good business relationship is important to nurture both financial and non-financial performances of a business.

\section{Research framework}

All the dependent and independent constructs of this study are latent constructs which are measured using sets of items. Upon reviewing previous literatures, the research framework of our study was obtained as in

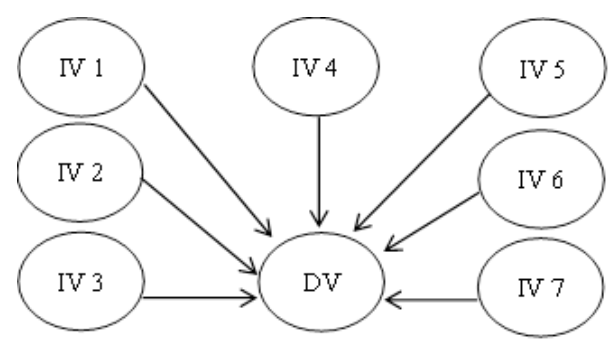

Figure 2 Conceptual framework of the study

\section{Data Analysis}

Data obtained through the interview were then analysed using Statistical Package for Social Sciences (SPSS) Version 20.0 Software. Exploratory Factor Analysis (EFA) was conducted to reduce the dimension, and test the construct validity (Awang and Mohamad, 2016). A total of 61 items (9 for DV and 52 for IVs) were reduced into eight variables (1 DV and $7 \mathrm{IVs}$ ). For each variable hypothesised, the sampling adequacy was ensured using Kaiser-Meyer-Olkin test (KMO) and Bartlett's test of sphericity. According to Yusoff (2010), the sample is considered adequate for factor analysis only if the KMO value was more than 0.5 and Bartlett's test was significant with p-value below 0.005. After ensuring the sampling adequacy, Principal Component Analysis (PCA) was conducted to extract components out of the latent constructs. With the assumption that all items are independent of each other, Varimax rotation was applied to optimise the loading factor of each item in the components. Then, items with low factor loading and cross loadings (redundant items) were removed in order to obtain unidimensionality (Awang, 2015). As this framework is newly constructed, only items with factor loading below 0.5 were removed (Abdullahi, 2016). Upon obtaining the components, the total variance explained (TVE) of each factor is obtained to ensure the degree of coverage of all the components of each factor. According to Abdullahi (2016), TVE exceeding 60\% indicates acceptable level of completeness of the items explaining a variable. In addition to that, reliability of each construct was also ensured by observing the Cronbach's alpha value.

High value of reliability of construct indicates that those items when used to study the same population would produce similar result. According to Hinton, McMurray and Brownlow (2014), Cronbach's alpha values exceeding 0.5 and 0.7 indicatemoderate and high reliability of the instrument respectively. 


\section{Results and discussion}

To facilitate easier understanding, the results for each constructs would be discussed in different sections.

Business Sustainability (DV)

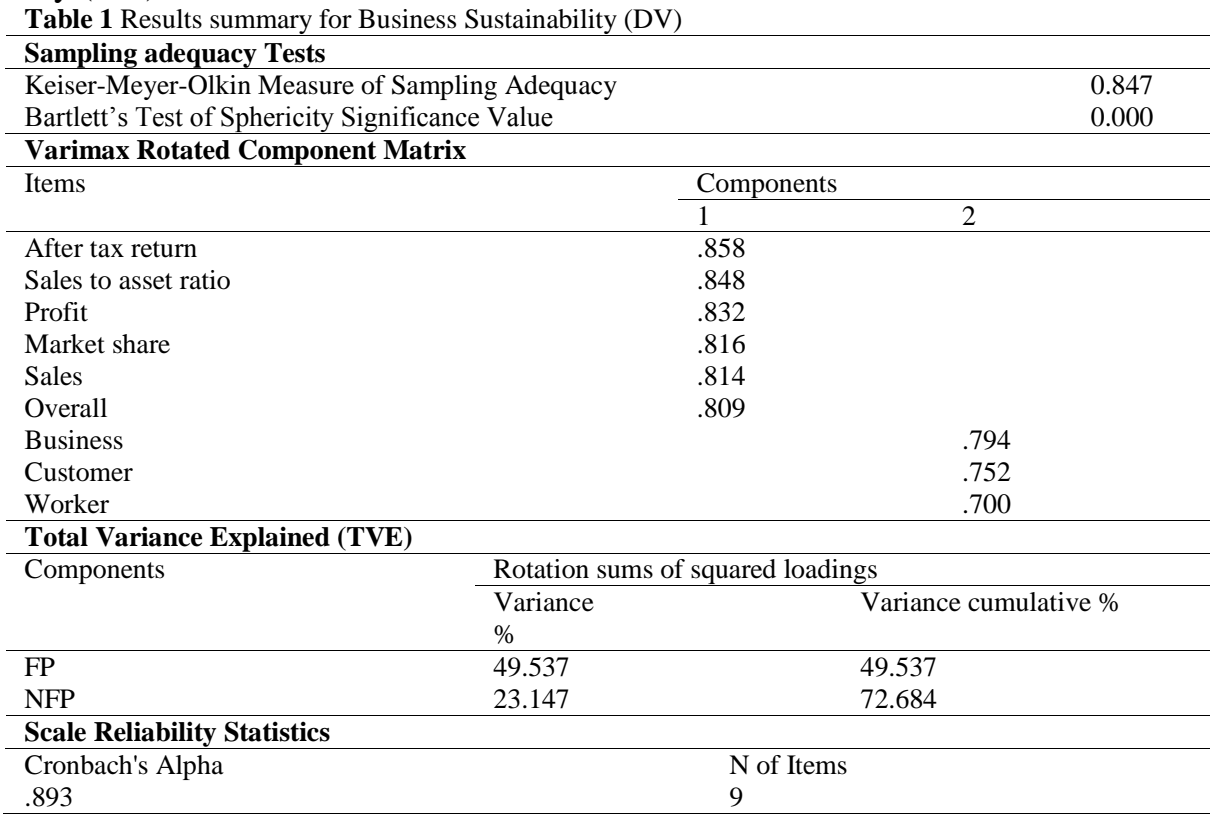

From Table 1, it is clear that sampling adequacy was achieved as both KMO sampling adequacy test value $(\mathrm{KMO}=$ $0.847>0.5)$ and Bartlett's Sphericity test significance value $(\mathrm{p}=0.000<0.005)$ are statistically acceptable. Apart from that, all nine (9) items used to measure business sustainability had factor loading above 0.5 and departed into two (2) components, namely financial performance (FP) and non-financial performance (NFP) with a TVE value of $72.684 \%$ exceeding the threshold of $60 \%$. The scale reliability is also ensured when a significant Cronbach's alpha value $(0.893$ $>0.5$ ) is achieved. Therefore it is justified that both the sample and scale used in this study is adequate and reliable to measure the dependent variable, namely business sustainability.

\section{Business Passion and Motivation (IV 1}

Table 2 Results summary for Business Passion and Motivation (IV1)

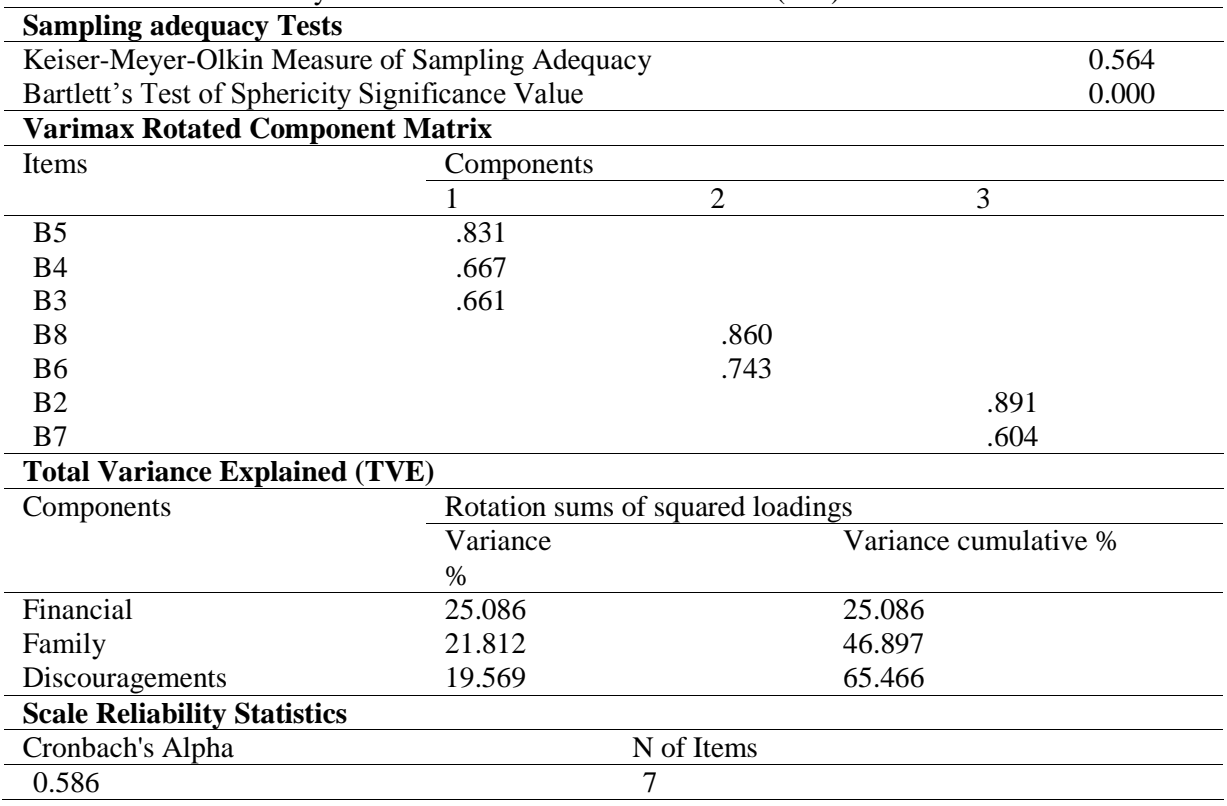


From Table 2, it is clear that sampling adequacy was achieved as both KMO sampling adequacy test value $(\mathrm{KMO}=$ $0.564>0.5)$ and Bartlett's Sphericity test significance value $(\mathrm{p}=0.000<0.005)$ are statistically acceptable. Apart from that, all seven (7) items used to measure business passion and motivation had factor loading above 0.5 and departed into three (3) components, financial, family and discouragements with a TVE value of $65.466 \%$ exceeding the threshold of $60 \%$. The scale reliability is also ensured when a significant Cronbach's alpha value $(0.586>0.5)$ is achieved. Therefore it is justified that both the sample and scale used in this study is adequate and reliable to measure the independent variable, namely business passion and motivation.

Owner and Business Traits (IV 2)

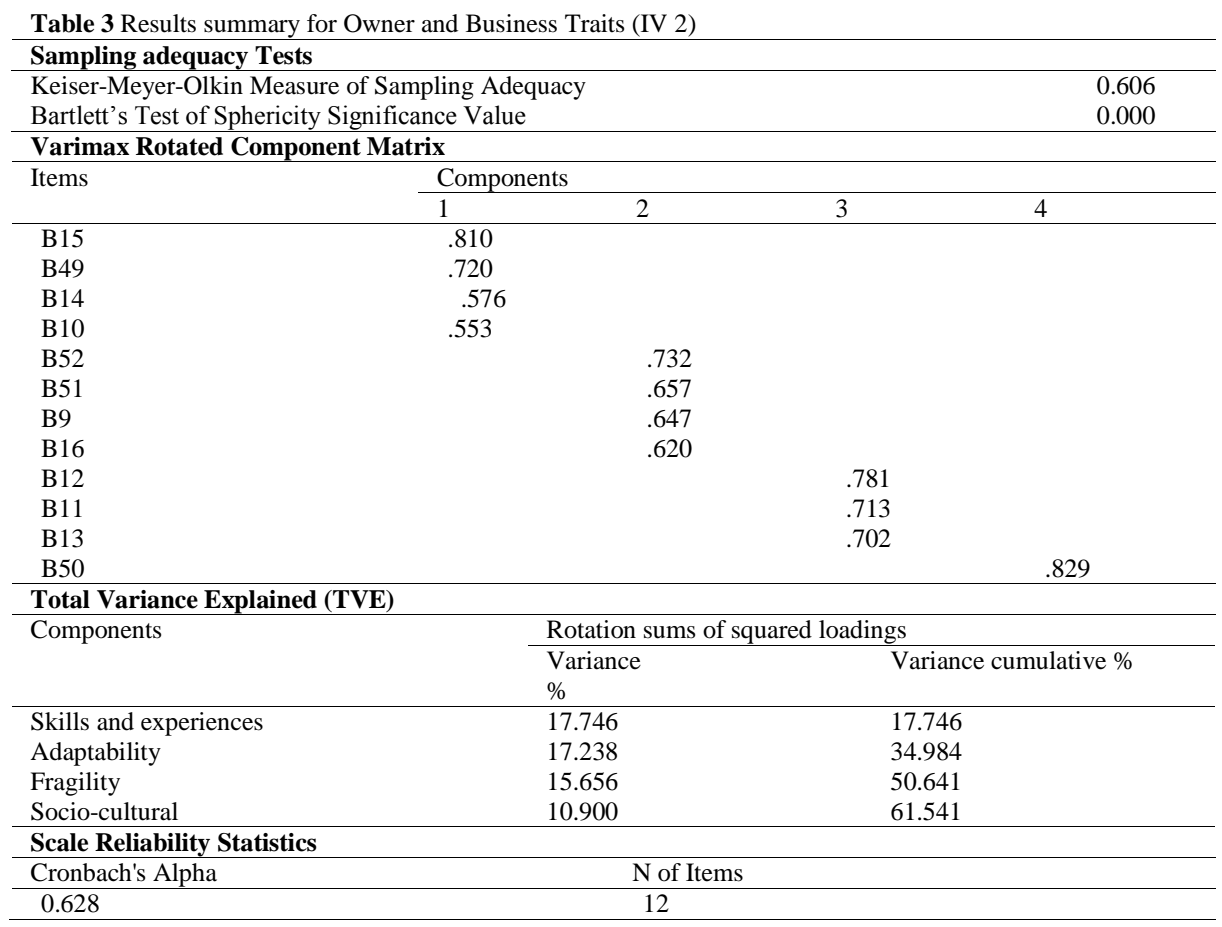

From Table 3, it is clear that sampling adequacy was achieved as both KMO sampling adequacy test value $(\mathrm{KMO}=$ $0.606>0.5)$ and Bartlett's Sphericity test significance value $(\mathrm{p}=0.000<0.005)$ are statistically acceptable. Apart from that, all twelve (12) items used to measure owner and business traits had factor loading above 0.5 and departed into four (4) components, skills and experiences, adaptability, fragility and socio-cultural with a TVE value of $61.541 \%$ exceeding the threshold of $60 \%$. The scale reliability is also ensured when a significant Cronbach's alpha value $(0.628$ $>0.5$ ) is achieved. Therefore it is justified that both the sample and scale used in this study is adequate and reliable to measure the independent variable, namely owner and business traits.

\section{Business Planning (IV 3)}

Table 4 Results summary for Business Planning (IV 3)

Sampling adequacy Tests

Keiser-Meyer-Olkin Measure of Sampling Adequacy $\quad 0.501$

Bartlett's Test of Sphericity Significance Value

Component Matrix

\begin{tabular}{ll}
\hline \multirow{2}{*}{ Items } & Components \\
\cline { 2 - 2 } & 1 \\
\hline B15 & .878 \\
B49 & .878 \\
\hline Total Variance Explained (TVE) & \\
\hline Constructs & Rotation sums of squared loadings \\
\cline { 2 - 2 } & Variance \% \\
\hline Business planning & 77.070 \\
\hline Scale Reliability Statistics & \multicolumn{2}{c}{ N of Items } \\
\hline Cronbach's Alpha & 2 \\
\hline 0.703 & \\
\hline
\end{tabular}


From Table 4, it is clear that sampling adequacy was achieved as both KMO sampling adequacy test value $(\mathrm{KMO}=$ $0.501>0.5)$ and Bartlett's Sphericity test significance value $(\mathrm{p}=0.000<0.005)$ are statistically acceptable. Apart from that, all two (2) items used to measure business planning had factor loading above 0.5 with a TVE value of $77.070 \%$ exceeding the threshold of $60 \%$. The scale reliability is also ensured when a significant Cronbach's alpha value $(0.703$ $>0.5)$ is achieved. Therefore it is justified that both the sample and scale used in this study is adequate and reliable to measure the independent variable, namely business planning.

Organisational Management (IV 4)

Table 5 Results summary for Organisational Management (IV 4)

Sampling adequacy Tests

\begin{tabular}{ll}
$\begin{array}{l}\text { Keiser-Meyer-Olkin Measure of Sampling Adequacy } \\
\text { Bartlett's Test of Sphericity Significance Value }\end{array}$ & 0.501 \\
\hline Component Matrix & \\
\hline Items & Components \\
\cline { 2 - 2 } & 1 \\
\hline B19 & 0.833 \\
B20 & 0.833 \\
\hline Total Variance Explained (TVE) & \\
\hline Constructs & Rotation sums of squared loadings \\
\cline { 2 - 2 } & Variance \% \\
\hline Organisational management & 69.437 \\
\hline Scale Reliability Statistics & \multicolumn{1}{c}{ N of Items } \\
\hline Cronbach's Alpha & 2 \\
\hline 0.543 & 2 \\
\hline
\end{tabular}

From Tables 5, it is clear that sampling adequacy was achieved as both KMO sampling adequacy test value $(\mathrm{KMO}=$ $0.501>0.5)$ and Bartlett's Sphericity test significance value $(\mathrm{p}=0.000<0.005)$ are statistically acceptable. Apart from that, all two (2) items used to measure organisational management had factor loading above 0.5 with a TVE value of $69.437 \%$ exceeding the threshold of $60 \%$.

The scale reliability is also ensured when a significant Cronbach's alpha value $(0.543>0.5)$ is achieved. Therefore it is justified that both the sample and scale used in this study is adequate and reliable to measure the independent variable, namely organisational management.

\section{Resource Management (IV 5)}

Table 6 Results summary for Resource Management (IV 5)

\section{Sampling adequacy Tests}

Keiser-Meyer-Olkin Measure of Sampling Adequacy $\quad 0.601$

Bartlett's Test of Sphericity Significance Value $\quad 0.000$

Varimax Rotated Component Matrix

\begin{tabular}{llll} 
Items & \multicolumn{2}{l}{ Components } & \\
\cline { 2 - 3 } & 1 & 2 & \\
\hline B28 & .835 & & \\
B27 & .802 & & \\
B29 & .637 & .794 & \\
B21 & & .779 & .808 \\
B24 & & .626 & .754 \\
B26 & & & .593 \\
B22 & & & \\
B23 & & & \\
B25 & & & \\
\hline
\end{tabular}

Total Variance Explained (TVE)

\begin{tabular}{lll}
\hline Components & \multicolumn{2}{l}{ Rotation sums of squared loadings } \\
\cline { 2 - 3 } & $\begin{array}{l}\text { Variance } \\
\%\end{array}$ & Variance cumulative \% \\
\hline Financial capital & 25.528 & 25.528 \\
Human capital & 19.416 & 44.945 \\
Management & 18.778 & 63.723 \\
\hline Scale Reliability Statistics & \multicolumn{2}{|}{} \\
\hline Cronbach's Alpha & \multicolumn{2}{l}{ N of Items } \\
\hline 0.714 & 9 \\
\hline
\end{tabular}


From Table 6, it is clear that sampling adequacy was achieved as both KMO sampling adequacy test value $(\mathrm{KMO}=$ $0.601>0.5)$ and Bartlett's Sphericity test significance value $(\mathrm{p}=0.000<0.005)$ are statistically acceptable. Apart from that, all nine (9) items used to measure resource management had factor loading above 0.5 and departed into three (3) components, namely financial capital, human capital and management with a TVE value of $63.723 \%$ exceeding the threshold of $60 \%$. The scale reliability is also ensured when a significant Cronbach's alpha value $(0.714>0.5)$ is achieved. Therefore it is justified that both the sample and scale used in this study is adequate and reliable to measure the independent variable, namely resource management.

\section{Production and Marketing Management (IV 6)}

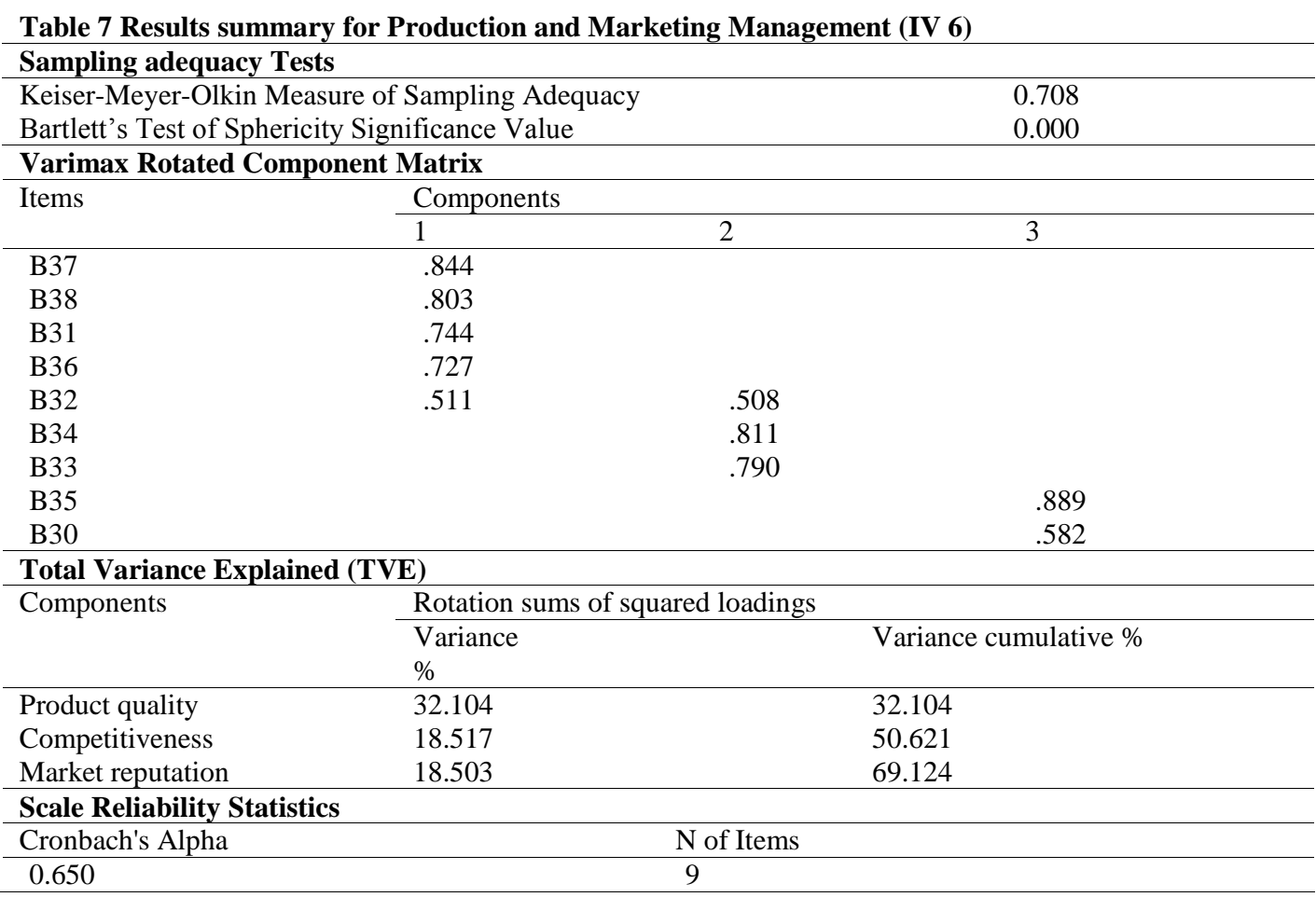

From Table 7, it is clear that sampling adequacy was achieved as both KMO sampling adequacy test value $($ KMO $=$ $0.708>0.5)$ and Bartlett's Sphericity test significance value $(\mathrm{p}=0.000<0.005)$ are statistically acceptable. Apart from that, all nine (9) items used to measure production and marketing management had factor loading above 0.5 and departed into three (3) components, namely product quality, competitiveness and market reputation with a TVE value of $69.124 \%$ exceeding the threshold of $60 \%$. The scale reliability is also ensured when a significant Cronbach's alpha value $(0.650>0.5)$ is achieved. Therefore it is justified that both the sample and scale used in this study is adequate and reliable to measure the independent variable, namely production and marketing management. 


\section{Business Relationships (IV 7)}

Table 8 Results summary for Business Relationships (IV 7)

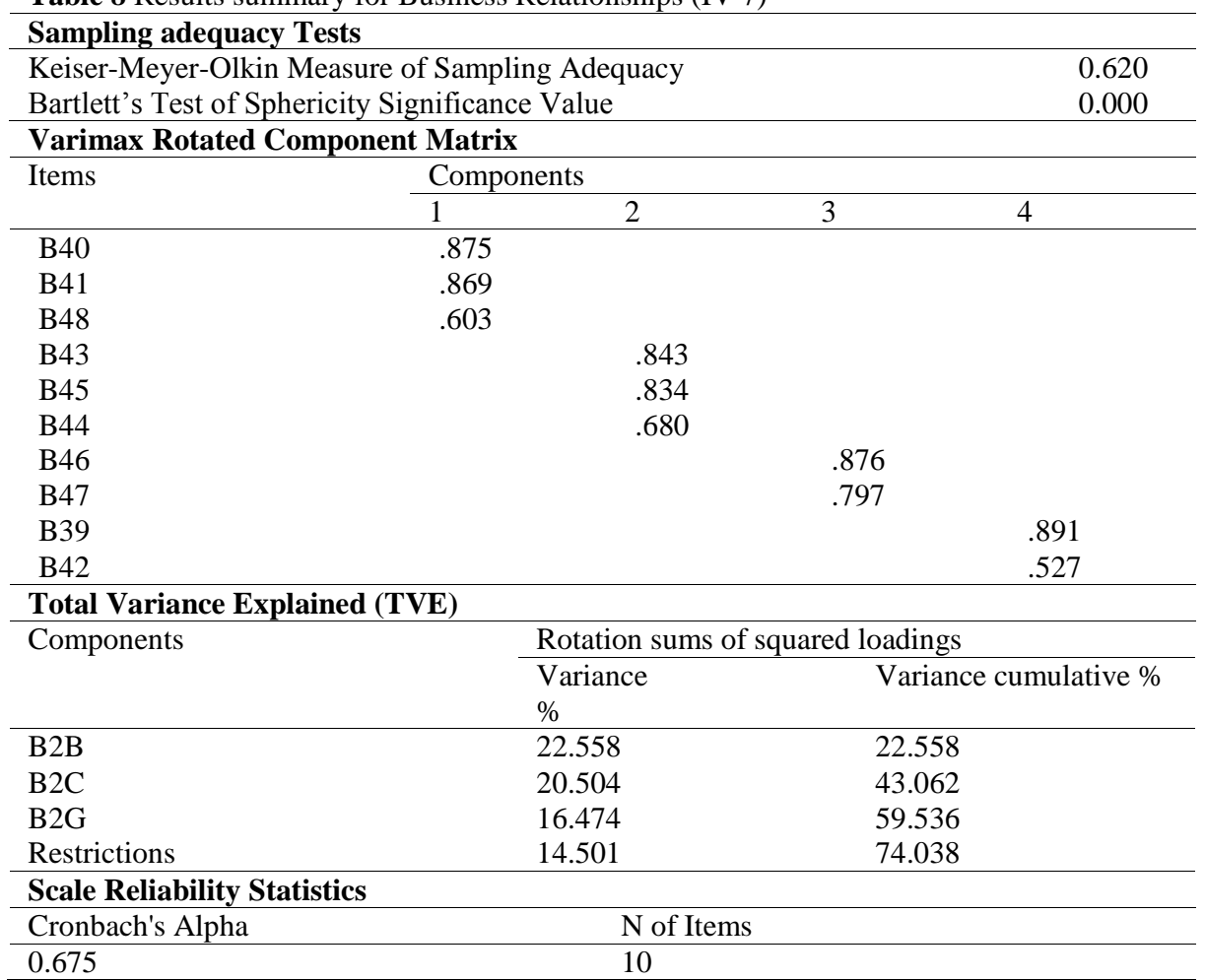

From Table 8, it is clear that sampling adequacy was achieved as both KMO sampling adequacy test value $(\mathrm{KMO}=$ $0.620>0.5)$ and Bartlett's Sphericity test significance value $(\mathrm{p}=0.000<0.005)$ are statistically acceptable. Apart from that, all twelve (12) items used to measure business relationships had factor loading above 0.5 and departed into four (4) components, business to business (B2B) relationship, business to customer (B2C) relationship, business to government $(\mathrm{B} 2 \mathrm{G})$ relationship and restrictions with a TVE value of $74.038 \%$ exceeding the threshold of $60 \%$. The scale reliability is also ensured when a significant Cronbach's alpha value $(0.675>0.5)$ is achieved. Therefore it is justified that both the sample and scale used in this study is adequate and reliable to measure the independent variable, namely business relationships.

\section{Conclusion}

In a nutshell, the objective of the study is achieved, by which, items were reduced into eight (8) variables, including one (1) dependent variable (DV), two (2) first order independent variables (IV 3 and IV 4) and (5) second order independent variables ( IV 1, IV2, IV 5, IV 6, IV 7). Sampling adequacy was obtained for every variable, indicating that data is suitable for factor analysis. Apart from that all the factors estimated in the theoretical framework were statistically justified to influence business sustainability and have TVE above $60 \%$. In addition to that, scale reliability also were ensured between moderate to high reliability, which means our instrument is applicable to study the factors of business sustainability among Malaysian ASMEs.

However, this finding might differ due to heterogeneity of sectors, location and time frame. Besides that, the strength and type of relationship among the variables need further validation through a Confirmatory Factor Analysis (CFA). This study is expected to be the start-up booster for further sector-specific researches integrating both financial and non-financial aspects of business sustainability.

\section{Acknowledgement}

This work was supported by the Fundamental Reseach Grant Scheme (FRGS) with project code FRGS/1/2015/SS03/UNISZA/02/2. We would like to thank Ministry of Higher Education of Malaysia and Universiti Sultan Zainal Abidin (UniSZA) for their endless supports and motivation on completing this project. 


\section{References}

Abdullahi, M.S. (2016). The effect of finance, infrastructure and training on the performance of small medium enterprises (SMEs) in Nigeria: Exploratory factor analysis and confirmatory factor analysis/ measurement model. The American Journal of Innovative Research and Applied Sciences.

Ali Salman, S. and Ndubisi, N.O. (2006). An evaluation of SME development in Malaysia. International Review of Business Research Papers.

Arumugam, N., Dhayalan, A., Zainol, F.A. and Boniface, B. (2017a). Theory and measures used in addressing agribusiness SMEs' sustainability: A mapping review of recent literatures. International Journal of Academic Research in Business and Social Sciences, 7(7): 872-885.

Arumugam, N., Dhayalan, A., Zainol, F.A. and Boniface, B. (2017b). Uncovering factors associated with Malaysian agribusiness small medium enterprises (ASMEs) business sustainability: A qualitative approach. Middle-East Journal of Scientific Research, 25(6): 1207-1215.

Awang, Z. (2015) SEM made simple. Bandar Baru Bangi, Selangor: MPWS Rich Publications Sdn. Bhd.

Awang, Z. and Mohamad, M. (2016) Postgraduate research proposal: a step by step guide in writing proposal for postgraduate students. Bandar Baru Bangi, Selangor: MPWS Rich Publications Sdn. Bhd.

Bonaventure, B., Gyau, A., and Stringer, R. (2012). Linking price satisfaction and business performance in Malaysia's dairy industry. Asia Pacific Journal of Marketing and Logistics, 24(2): 288-304. Retrieved on August 17th, 2014 from http://www.emeraldinsight.com

CODIT: The Institute of Community and Organizational Development. (2009). Beekeeping/ honey value chain financing study report. Nairobi: CODIT.

Comparison of the ISPO, MSPO and RSPO (n.d.). In Efeca economics climate environment Website. Retrieved on October 29th 2017 from http://www.efeca.com/wp-content/uploads/2016/03/Efeca_PO-StandardsComparison-.pdf

Copper, A.C. and Artz, K.W. (1999). Determinants of satisfaction for entrepreneurs. Journal of Business Venturing 10(6): 439-457

Darcy, C., Hill, J., McCabe, T.J., and McGovern, P. (2014). A consideration of organisational sustainability in the SME context: A resource-based view and composite model. European Journal of Training and Development, 38(5): 398-414. Retrieved on October 28th, 2017 from https://doi.org/10.1108/EJTD-10-2013-0108.

Dlamini, B.P. (2014). Factors affecting the competitiveness of the agribusiness sector in Swaziland. Journal of agricultural studies, 2(1): 61-72.

Escalante, C.L. and Turvey, C.G. (2006). Business start-up survival challenges and strategies for agribusiness and nonagribusiness entrepreneurs. Agricultural Finance review, 66(1): 61-75. Retrived on February 22nd, 2015 from http://www.emeraldinsight.com

Falshaw, J.R. and Glaister, K.W. (2006). Evidence on formal strategic planning and company performance. Journal of Managing Decission. 44(1): 9-30. Retrieved on June 25th, 2016 from http://www.emeraldinsight.com

Friedrich, N., Heyder, M. and Theuvsen, L. (2013). Sustainability management in agribusiness: challenges, concepts, responsibilities and performance. Department of Agricultural and Rural Development, Georg-August University of Gottingen: Germany.

Gao, J. and Bansal, P. (2013). Instrumental and integrative logics in business sustainability. Journal of Business Ethics. 112: 241-255. Retrieved on June 25th, 2016 from http://www.link.springer.com

Hinton, P.R., McMurray, I., and Brownlow, C. (2014). SPSS explained. Howick Place, London: Routledge Taylor and Francis Group.

KiatGan, C. and Mahmoud Khalid, A. (2013). The determinants of SME succession in Malaysia, from entrepreneurship perspective. Journal of Advanced Social Research, 3(12): 350-361.

Kraaijenbrink, J. and Spender, J.C. and Groen, A.C. (2009). The resource based view: a review and assessmet of its critiques, Munich Personal RePEc Archive.

Lightelm, A.A. (2010). Entrepreneurship and small business sustainability. Southern African Business Review. 14(3): 131-153. Retrieved on June 25th, 2016 from http://www.unisa.ac.za

Mahfoor, H.H., Mad Nasir, S. and Ismail, A.L. (2001). Challenges for agribusiness: a case for Malaysia. Paper presented at International Symposium on Agribusiness Management towards Strengthening Agricultural Development and Trade, Chiang Mai University.

Mahto, R.V., Davis, P.S., Pearce II, J.A., and Robinson Jr., R.B. (2010). Satisfaction with firm performance in family business. Entrepreneurship Theory and Practice, 34(5): 985-1001. 
Michel-Villarreal, M.d.R. and Vilalta-Perdomo, E. (2016, May). An initial exploration on the drivers for integrating small-farmers in supply chains and networks: Prospensity to collaborate. Paper presented at 2016 industrial and systems engineering research conference, Anaheim, CA. Retrieved on July 17th, 2016 from https://www.researchgate.net/publication/299532645

Mohd Mansor, I. (2014). Competitiveness of beekeeping industry in Malaysia. Serdang, Selangor: Universiti Putra Malaysia.

Mudavanhu, V., Bindu, S., Chigusiwa, L., and Muchabaiwa, L. (2011). Determinants of small and medium enterprises failure in Zimbabwe: A case study of Bindura. International Journal of Economic Research, 2(5): 82-89. Retrieved on July 15th, 2016 from http://www.ijeronline.com

National SMEs Development Council (NSDC). (2017). Laporan Tahunan PKS 2015/6.

Noor Hazlina, A. and Pi-Shen, S. (2009). Dissecting behaviour associated with business failure: A qualitative study of SME owners in Malaysia and Australia.

Okoye,A.C., Mbanasor, J.A., Okoye,B.C., and Nto.P.O.O. (2013). Determinants of survival among agribusiness enterprises in Ebonyi State, Nigeris. International Center for Business Research, 2(9): 64-70.

Olabisi, S.Y. and Olagbemi, A.A. (2011). Factors affecting small-scale business performance in informal economy in Lagos state- Nigeria: A gendered based analysis. Lagos: Lagos State University.

Ramayah, T. Ling, N.S., Taghizadeh, S.K., Abidur Rahman, S. (2016). Factors influencing SMEs website continuance intention in Malaysia. Telematics and Informatics, 33: 150-164.

Ramli, S.A., Abu Samah, B., Hassan, M.S., Omar, S.Z., Bolong, J., and Mohamed Shaffri, H.A. (2015). Potential benefits of ICT for youth agro-based entrepreneurs in Malaysia. Journal of Applied Sciences.

Ramukumba,T. (2014). Overcoming SME challenges through critical success factors: A case of SMEs in the western Cape Province, South Africa. Economic and business review, 16(1): 19-38.

Rozhan, A.D. (2015). Transformation of agricultural sector in Malaysia through agricultural policy. Malaysian Agricultural Research and Development (MARDI): Malaysia.

Semistatus, H.M. and Rainer, K. (2014). Performance of micro and small-scale enterprises in Tanzania: growth hazards of fruit and vegetables processing vendors. Journal of Applied Economics and Business Research. 4(2): 120133.

Siti Sarah, O., Lawrence, A., and Maimunah,I. (2009). The background and challenges faced by small medium enterprises. A human resource development perspective. International journal of business and management, 4(10): 95-102. Retrieved on November 3rd, 2015 from http://www.ccsenet.org

Stephen, U., Hart, M., and Mickiewicz, T. (2015). Understanding motivations for entrepreneurship. Bis Research Paper. 3(212): 1-109. Department for Business Innovation and Skills: London, United Kingdom. 